NBER WORKING PAPER SERIES

WHAT IS THE MARGINAL BENEFIT OF PAYMENT-INDUCED FAMILY CARE?

\author{
Norma B. Coe \\ Jing Guo \\ R. Tamara Konetzka \\ Courtney Harold Van Houtven \\ Working Paper 22249 \\ http://www.nber.org/papers/w22249 \\ NATIONAL BUREAU OF ECONOMIC RESEARCH \\ 1050 Massachusetts Avenue \\ Cambridge, MA 02138 \\ May 2016
}

We would like to acknowledge Barbara Schone, participants in the PHEnOM seminar at the University of Washington, American Economic Association annual meetings, and the International Conference on Evidence-based Policy in Long-Term Care for their helpful comments on previous versions of this paper. Any errors are our own. The views expressed herein are those of the authors and do not necessarily reflect the views of the National Bureau of Economic Research.

NBER working papers are circulated for discussion and comment purposes. They have not been peer-reviewed or been subject to the review by the NBER Board of Directors that accompanies official NBER publications.

(C) 2016 by Norma B. Coe, Jing Guo, R. Tamara Konetzka, and Courtney Harold Van Houtven. All rights reserved. Short sections of text, not to exceed two paragraphs, may be quoted without explicit permission provided that full credit, including $\odot$ notice, is given to the source. 
What is the Marginal Benefit of Payment-Induced Family Care?

Norma B. Coe, Jing Guo, R. Tamara Konetzka, and Courtney Harold Van Houtven

NBER Working Paper No. 22249

May 2016

JEL No. I1,I13,I28

\section{ABSTRACT}

Research on informal and formal long-term care has centered almost solely on costs; to date, there has been very little attention paid to the benefits. This study exploits the randomization in the Cash and Counseling Demonstration and Evaluation program and instrumental variable techniques to gain causal estimates of the effect of family involvement in home-based care on health care utilization and health outcomes. We find that family involvement significantly decreases Medicaid utilization. Importantly, we find family involvement significantly lowers the likelihood of urinary tract infections, respiratory infections, and bedsores, suggesting that the lower utilization is due to better health outcomes.

Norma B. Coe

H-683 Health Sciences Building

Box 357660

University of Washington

1959 NE Pacific

Seattle, WA 98195

and NBER

nbcoe@uw.edu

Jing Guo

American Institutes for Research 6003 Executive Blvd

Suite 300

North Bethesda, MD 20852

jguo@air.org
R. Tamara Konetzka

University of Chicago

5841 S. Maryland Ave., MC 2007, Rm. W-255

Chicago, IL 60637-1447

tkonetzk@health.bsd.uchicago.edu

Courtney Harold Van Houtven

Department of Medicine

Division of General Internal Medicine

Duke University Medical Center

Durham, NC 27705

courtney.vanhoutven@duke.edu 


\title{
What is the Marginal Benefit of Payment-Induced Family Care?
}

Norma B. Coe, University of Washington and NBER

Jing Guo, American Institutes for Research

R. Tamara Konetzka, University of Chicago

Courtney Harold Van Houtven, Duke University and the Durham VA

\begin{abstract}
:
Research on informal and formal long-term care has centered almost solely on costs; to date, there has been very little attention paid to the benefits. This study exploits the randomization in the Cash and Counseling Demonstration and Evaluation program and instrumental variable techniques to gain causal estimates of the effect of family involvement in home-based care on health care utilization and health outcomes. We find that family involvement significantly decreases Medicaid utilization. Importantly, we find family involvement significantly lowers the likelihood of urinary tract infections, respiratory infections, and bedsores, suggesting that the lower utilization is due to better health outcomes.
\end{abstract}

Acknowledgements: We would like to acknowledge Barbara Schone, participants in the PHEnOM seminar at the University of Washington, American Economic Association annual meetings, and the International Conference on Evidence-based Policy in Long-Term Care for their helpful comments on previous versions of this paper. Any errors are our own. 


\section{Introduction}

Well-known demographic trends point to an increasing need for health care services in coming decades, especially among individuals with long-term care (LTC) needs (CDC, 2003). Long-term care is generally defined as the need for ongoing assistance due to functional or cognitive impairment, the risks of which increase with age. How best to meet this need should depend on an assessment of the costs and benefits of each potential source and type of care, including care from family members, but the evidence base to inform such decisions is sparse.

Historically, effective demand for long-term care services has been constrained by both personal finances and policy, with the intersection of the two often determining the type of assistance. Medicare provides little to no LTC insurance coverage, and the private LTC insurance market is small. Currently around 15 percent of individuals age 65+ have private longterm care insurance coverage, leaving many individuals to pay out of pocket. The median cost of a home care aide providing 44 hours of home care per week is almost $\$ 46,000$ annually (Genworth, 2016), which still may pose a significant barrier for many elderly, who then must rely on unpaid, untrained care from family and friends.

With limited coverage under Medicare and private insurance, Medicaid has become and likely will continue to be the primary payer of formal LTC. Medicaid traditionally paid only for nursing home care, creating concern about an institutional bias in the program; individuals may be able to be served in the community, at potentially lower costs, if there were no financial barriers to access this care at home. To address this concern, increasingly, home- and community-based alternatives are also covered by state Medicaid programs. However, while these programs decrease the bias toward nursing home use, they have not necessarily proved to be cost-saving.(Weissert et al., 2003) Medicaid currently spends $\$ 55$ billion a year on home- and 
community-based long-term care, surpassing its annual spending on nursing homes (O'Shaughnessy, 2013). Moreover, shifting care to the home inevitably increases the role of family caregivers (Konetzka, 2014). Whereas there is a movement to further increase public funding for home care over institutional long-term care, increasing longevity and strained budgets have led many policymakers to advocate for increased reliance on unpaid care from family and friends as a potential substitute for paid home care.

Informal, usually uncompensated care from family and friends currently makes up the bulk of LTC provision. Although definitive data are hard to come by, among American elderly living in the community with LTC needs, more than two-thirds rely exclusively on informal care and over 90\% rely on some informal care (O'Brien, 2005). Despite the fact that the two are often used together, unpaid care is typically viewed as an alternative to paid care. To date, research has focused on the relative costs of each type of care. From a narrow perspective of public payment, informal care is a vastly cheaper alternative to formal care, as it is provided "for free" by family and friends. However, from a societal perspective, unpaid care incurs potentially substantial costs, once one includes the labor market and health effects on the care providers themselves.(Arno et al., 1999; Baumgarten et al., 1992; Bloom et al., 2003; Christakis and Allison, 2006; Clyburn et al., 2000; Coe and Van Houtven, 2009; Haley et al., 2003; Haley et al., 2001; Harrow et al., 1995; Kiecolt-Glaser et al., 1991; King et al., 1994; Langa et al., 2001; Navaie-Waliser et al., 2002; Schulz and Beach, 1999; Schulz and Martire, 2004; Schulz et al., 2003; Schulz et al., 1995; Skira, In press; Small et al., 2002; Spillman and Pezzin, 2000; Stone et al., 1987; Vitaliano, 1997; Vitaliano et al., 
whether the informal care 'market' has the capacity to increase supply in order to meet the future demand (Johnson et al., 2007).

Perhaps more importantly, it is not yet known if there are differences in the benefit of home care based on the type of home-based LTC provider. The benefits of each type of care may be inferred only indirectly from studies of cost offsets between unpaid care and paid formal care. For example, studies have shown that unpaid family care is a net substitute for nursing home care, even after addressing the endogeneity of receiving informal care (Charles and Sevak, 2005; Greene, 1983; Lo Sasso and Johnson, 2002; Van Houtven and Norton, 2004, 2008). ENREF 28 ENREF 54 However, to assess the potential benefit from policies encouraging or supporting family caregiving, often used in conjunction with formal care, evidence on the marginal benefit of family care over and above formal care is needed.

Theoretically, the marginal benefit of family care on the care recipient's outcomes and costs is ambiguous. Formal home care is provided by trained staff, while family and friends are largely untrained, so it is possible that the care recipient suffers worse outcomes with family care. Family may also be less able to be objective about care needs and may disagree with formal caregivers, which could lead to friction and either underuse or overuse of inpatient care. On the other hand, family and friends likely have a stronger personal connection to the care recipient and may provide more diligent, reliable care, with less loss of information across care episodes than formal home care, where multiple caregivers may provide care at different times. Ultimately, the marginal benefit of family care remains an empirical question.

One problem that researchers face when assessing the relative benefits of family care empirically is that the care provider(s) assumes her role by choice, and this choice is likely correlated with unobserved baseline health or other factors, presenting an endogeneity problem. 
In order to surmount that problem, we use a unique setting that randomized Medicaid LTC recipients between two arms of care as part of the Cash and Counseling Demonstration and Evaluation program (CCDE). The control group had access to the default Medicaid home care: receiving care from a Medicaid-certified agency (hereafter called agency care). The treatment group received an allowance that could be used to pay for agency care and/or pay for care from family and friends (paid family care). For both treatment and control group patients, unpaid family care was also available, either in conjunction with or instead of the paid care options. The demonstration project essentially provides a randomized trial for the type of care received among recipients of Medicaid home care services, because randomized assignment had potential to encourage family care involvement in the treatment group. This randomization has previously been shown to predict with great precision subsequent use of agency care (Guo et al., 2014). No one has yet used this randomized trial to examine patient outcomes based on the mix of homebased care providers.

Patient outcomes are one way to measure the relative benefits of each types of care, an important step in informing appropriate policy. While nursing homes and home care agencies are mandated to report uniform clinical data in order to assess patient outcomes, these measures are not required and largely unavailable for those receiving family care. There is largely no regulation, no assessment of family caregiver skill, no certification, and yet there is very likely great heterogeneity and discrepancies in the skill required and the skill provided. Historically, the only measure of the benefit of unpaid care was adequacy, i.e. whether or not the care needs are routinely satisfied (Morrow-Howell et al., 1998; Morrow-Howell et al., 2001; Skinner et al., 1999). While this measure is useful to identify unmet needs in the community, it is quite limited in terms of assessing benefits. 
In this paper, we contribute to the broader literature on LTC financing and outcomes by providing the first rigorous estimates of the benefits of having family caregivers in addition to formal, agency-based home care. This is an area with a dearth of evidence due to limited data availability, yet such evidence is critical to appropriate policy development. We also contribute to the labor economics literature by examining whether the mix of caregivers matters for LTC outcomes. To inform the potential welfare implications of differences in costs and utilization, we examine health outcomes expected to be sensitive to the quality of home-based care. Overall, we assess patient health care and health outcomes and the relative financial gain or costs to the Medicaid system to assess the benefits of family involvement in home care. We exploit the randomization of the CCDE into different types of home care services to estimate the causal impact of family involvement in care on these patient outcomes pertinent to the Medicaid system.

This paper proceeds as follows. Section 1 details the relevant parameters of the CCDE program and how it addresses the endogeneity issues. Section 2 discusses our conceptual framework. Section 3 describes our data and our sample while Section 4 details our analysis methodology. Section 5 provides the results while section 6 discusses the generalizability of our findings. Section 7 concludes that payment-induced family care leads to substantial decreases in hospital spending and higher patient health within 9 months.

\section{Cash and Counseling Demonstration and Evaluation (CCDE) program}

CCDE was designed to assess whether a more flexible consumer-directed manner of receiving Medicaid home care services could improve the outcomes of beneficiaries and their caregivers without increasing Medicaid cost per recipient for such services (Dale and Brown, 
2007). Rather than randomizing all Medicaid recipients, the demonstration enrolled those eligible Medicaid beneficiaries with previous home care use who volunteered for the Cash and Counseling program and consented to randomization (Doty et al., 2007). Arkansas, New Jersey, and Florida participated in this three-state demonstration. Enrollment occurred from December 1998 through July 2002. While the overall CCDE evaluation included 24 months of follow-up, we use only the 9-month follow-up data due to the presence of the family care variable in relation to outcomes of interest. See Figure 1 for a timeline of the CCDE experiment and data used in this study.

The CCDE used a randomized experimental design, somewhat rare in social policy, to assess the effects of Cash and Counseling on the well-being of consumers and on the consumers' caregivers. After completing a baseline interview, half of the CCDE enrollees were assigned to the control group, where they received the standard Medicaid long-term care services secured through the traditional agency-based model. The other half were randomized into the treatment group, where, instead of in-kind benefits, they received a monthly allowance equal to the amount Medicaid would have paid for their care to be met under the traditional model. Recipients could use this allowance in the way they deemed best to meet their care needs: using agency care; hiring non-agency workers (including family members) directly; purchasing selected care-related goods and services. In addition, the treatment group was eligible for counseling services and supervision to help them to manage their home care needs and make sure that every purchase was for qualified goods and services.

The CCDE program was authorized through a section 1115 waiver, and thus was subject to the Center for Medicaid and Medicare Services (CMS)'s budget-neutrality condition on HCBS 
services. Therefore, the allowance received by individuals in the treatment group was set so that the expected cost per recipient was the same as if they were in the control group.

To be clear, individuals in both the treatment and control groups were eligible to receive agency-based home care, purchase durable medical equipment, and to receive unpaid care from family and friends. The key difference by arm for our purposes is that individuals in the treatment group were able to use Medicaid dollars to purchase care from non-agency sources, including friends and family. In part because Medicaid home care agencies were usually less available or more expensive than privately hired caregivers (Doty et al., 2007), individuals randomly assigned to the treatment group were more likely to use family care in addition to agency care than those in the control group, who could use Medicaid money only to pay for agency care (See Table 3).

This paper is not evaluating the CCDE itself, which has been widely studied. For example, previous research found that CCDE led to significantly reduced unmet needs of participants and greater satisfaction with care (Carlson et al., 2007b). While the CCDE led to no change in health outcomes (Carlson et al., 2007b) for the care recipient, it has been shown that it improved quality of life for participants and their caregivers (Carlson et al., 2007b; Foster et al., 2007). However, the CCDE did lead to higher Medicaid personal care costs, mainly because enrollees received more of the care they were authorized to receive. These increased costs were partially offset by other cost savings in institutional and other long-term care (Brown et al., 2007).

Instead, we are taking advantage of the rare opportunity of the CCDE's randomized control study design to answer a very different question which has not yet been addressed. The 
randomization caused individuals in the treatment group to use a different mix of care providers than those in the control group. The randomization addresses the endogeneity of the choice of long-term care delivery and allows us to estimate the marginal benefit of family care over and above agency care. We control for the other effects of the CCDE program in order to isolate the impact of care delivery mix on health outcomes and spending.

\section{Data and Measurement}

2.1 Data. The primary data sources for this project include 1998-2003 Medicaid claims data for adult enrollees of the Cash and Counseling Demonstration and Evaluation (CCDE) program, the baseline CCDE survey, and a 9-month follow-up CCDE survey. ${ }^{1}$

2.2 Sample. The main analysis of this study limits the sample to 4,972 adults who were continuously enrolled in Medicaid during the first year post-randomization of the CCDE study period and answered the 9-month follow-up survey. ${ }^{2}$ We also conduct sub-sample analysis based on age $(<65,65+)$, and by living situation (alone vs. with others) to test for heterogeneity of the effect of family involvement in care (Brookes et al., 2001). ${ }^{3}$

\footnotetext{
${ }^{1}$ The CCDE Medicaid claims data are publicly available on the Web at http://198.87.1.39/ccda/.

${ }^{2}$ Tests on baseline variables comparing the treatment arms suggest that this sample exclusion does not appear to introduce statistically significant selection bias to the randomized study at a 10 percent significant level based on observed variables. 94\% of pre-randomization attributes were not significantly different across the two groups at a 5 percent significant level. ${ }^{3}$ Age was pre-specified as a factor in the randomized control trial in order to allow sub-sample analysis. While living arrangement was not pre-specified or used in the randomizations, we conduct statistical tests (see Table 2) to see if the observable characteristics are balanced between
} 
2.3 Outcome Measures. The dependent variables of interest are hospital utilization and nominal costs covered by Medicaid, derived from the Medicaid claims data at 9 months postrandomization, and self-reported health outcomes, all from the 9-month follow-up survey. In terms of our cost-related outcomes, we adopt the perspective of the Medicaid program for this paper. Besides being dictated by data availability (as we have no data on Medicare or private payer spending), focusing on Medicaid spending is critical because it is a major player in the home care market, especially to address chronic long-term care needs. We use "costs" to refer to costs to (or spending by) the Medicaid program. The hospital utilization measures we examine include: any emergency room use; any hospital inpatient days; the number of inpatient hospital days; time until hospitalization; any Medicaid inpatient spending; the number of months with inpatient spending; and the total Medicaid inpatient expenditure. In terms of types of utilization, focusing on the outcome of inpatient care is critical because inpatient care is very expensive, and because of recent and growing attention to inpatient admissions and readmissions as incentivized patient-centered outcomes under the Affordable Care Act (ACA).

There are 6 binary health outcomes measures in the 9-month survey. First, consumers can indicate if their current health is poor relative to their peers. Second, we know if two types of infections have occurred since the baseline interview: urinary tract infections and respiratory

the treatment and controls within this subgroup. We conduct our sub-analyses by re-estimating the equations on the specific subpopulation instead of including interaction terms into the model. The samples of interest are 2,241 (age < 65) and 3,508 (living alone), , at least 10 times larger than the minimum suggested size of 200 suggested by Brookes et al. (2001) where the methods are asymptotically equivalent. 
infections. Finally, we have three indicators of the presence or worsening of three conditions: bedsores, muscle contractures, and shortness of breath.

2.4 Explanatory Variables. The key explanatory variable is an indicator for family involvement in home care provision. If individuals report having received unpaid care, we assume this is from family and friends (thus family is involved in care). The receipt of unpaid care is consistent between the treatment and control groups; 77 percent of the control group and 78 percent of the treatment group received unpaid care. However, the treatment group was also allowed to use Medicaid dollars to pay family members, and 44 percent of the treatment group did so. We define having family involved in home care as having either unpaid care or indicating that any of the Medicaid payments went to related individuals. Although we have data on the total hours of home care, we do not have total hours separated by family vs agency care which would allow us to model the intensity of family care. Thus, we focus on the extensive margin and model receipt of family care as a dichotomous variable, controlling for total hours of care.

While claims data typically have limited demographic and socioeconomic information, we are able to use the baseline survey data, measured before randomization, to include as additional controls. These measures include non-time-varying (gender, race, and ethnicity) and time-varying demographic (age and marital status at baseline) information. In order to control for baseline health, we include a set of pre-randomization health status measures and health spending. The health status measures include an extensive list of health conditions, ranging from cancer and cardiovascular problems to psychological problems. We also control for two types of unpaid care received at baseline: transportation and house or community activities.

Finally, from previous research on the CCDE experiment, we know that the CCDE 
impacted care other than who was the home care provider, the channel of interest here. For example, the treatment group spent more on counseling services as designed, and received more hours of care overall (Carlson et al., 2007a; Doty et al., 2007; Foster et al., 2007). In order to isolate the effect of the home care provider on health outcomes, we include controls in the model for the amount of Medicaid dollars spent on counseling and hospice, as derived from the Medicaid claims data. The 9-month survey asked about the total hours of care provided in the previous two weeks for up to three visiting paid caregivers, three visiting unpaid caregivers, two live-in paid caregivers, and two live-in unpaid caregivers. We sum over all types and include the total hours, paid and unpaid, of home care received.

\section{Analytic approach}

3.1. Utilization and Expenditure Models. This study uses a two-part model (2PM) to estimate the impact of having family involvement in care on inpatient care use and spending, given the size of the zero-mass and skewed distribution of the outcome variables. The first part of the 2PM estimates the risk of any inpatient care use, or the probability of positive Medicaid inpatient care expenditures using a logit model, while the second part estimates the inpatient care days or the amount of Medicaid costs conditional on having any. Both parts are conditional on observed characteristics.

Specifically, we estimate the first part of the two-part model as:

$$
\operatorname{Pr}\left(Y_{i, t+9}>0 \mid X, F C, M, \sigma, \pi\right)=\operatorname{logit}^{-1}\left(\alpha+\beta_{1} F C_{i, t+9}+\beta_{2} M_{i, t+9}+\beta_{3} X_{i, t}+\sigma_{i}+\varepsilon(1)\right.
$$

where $\mathrm{Y}$ is the outcome of interest - emergency room days, inpatient length of stay, or inpatient spending. In the first part of the model we are estimating the probability of $\mathrm{Y}>0$, conditional on the controls, under the assumption of a standard logistic distribution of the error term. The 
independent variables include $F C_{i, t+9}$ as an indicator of whether family was involved in care received by patient $i$, as measured at ( $\mathrm{t}+9)$, month 9 after randomization. $M_{i, t+9}$ is a vector of controls for contemporaneous effects of CCDE, namely the spending on counseling, hospice care, the total number of paid and unpaid hours of home care received. Including these variables as controls helps to isolate the effect of family care versus agency care by eliminating other pathways to outcomes that may have been caused by the treatment. We control for the total number of care hours received, which might reflect differences in need across individuals and across treatment arms and could otherwise confound the effect of interest. ${ }^{4} X_{i, t}$ is a vector of individual demographic and socioeconomic variables, including gender, race (black or other race, white is reference), ethnicity (not Hispanic is reference), age measured in ranges (18-64 and age 80 and above, 65-79 is reference), potential informal care sources at baseline (marital status), two types of unpaid care received at baseline (transportation, house or community activities), and a set of pre-randomization health status variables (an extensive list of health conditions, ranging from cancer and cardiovascular problems to psychological problems), all measured at baseline. $\sigma_{l}$ is a state-fixed effect.

The second part of the model estimates the expenditure and utilization among individuals with any utilization of that type:

$$
Y_{i, t+9}=\alpha+\beta_{1} F C_{i, t+9}+\beta_{2} M_{i, t+9}+\beta_{3} X_{i, t}+\sigma_{i}+\pi
$$

where $\mathrm{Y}$ is the outcome variable of interest - inpatient length of stay, months with inpatient spending, or total inpatient spending, and the controls are as stated above. The expenditures and utilization among those with any inpatient care were right-skewed. To take this issue into

\footnotetext{
${ }^{4}$ Section 5.1 discusses the results without controlling for these additional factors.
} 
account in the second part and avoid the potential bias problems in retransformation, generalized linear models (GLM) (McCullagh and Nelder, 1989) are used and specified with log link and Gamma family based on a series of model specification tests.

3.2 Duration Model. Having family involved in care might impact not only the amount of care received, but also the timing of such care. We estimate the impact of family care on the time until hospitalization using a Cox proportional hazard model. This survival analysis treats death, Medicaid disenrollment, and end of CCDE program as random right-censoring events.

Specifically, we estimate

$$
h\left(t, Y_{i, t}\right)=h_{0}(t) \exp \left(\alpha+\beta_{1} F C_{i, t+9}+\beta_{2} M_{i, t+9}+\beta_{3} X_{i, t}+\sigma_{i}+e\right)
$$

where the covariates are as described above.

\subsection{Emergency Room Use and Patient Outcome Models.}

All six measures of patient health are binary outcomes. Additionally, we have an indicator for the use of an emergency room. For these outcomes we estimate a logit of the following form:

$$
\operatorname{Pr}\left(Y_{i, t+9}>0\right)=\operatorname{logit}^{-1}\left(\alpha+\beta_{1} F C_{i, t+9}+\beta_{2} M_{i, t+9}+\beta_{3} X_{i, t}+\sigma_{i}+\varepsilon_{i}\right)
$$

where $Y_{i}$ is the binary outcome of interest - one of the six health outcome of individual $i$ measured 9 months after randomization or the use of the emergency room. All controls are as defined above.

3.4 Endogeneity and instrumental variable approach. There are several major sources of potential endogeneity that need to be considered when estimating the causal effect of using 
family care on acute care use and costs. First, use of family care is likely to be correlated with unobserved factors, such as the availability and quality of informal care, home environment, or health characteristics of the participant, which may also affect acute care use or health outcome measures (omitted-variable bias). Second, family care and acute care may be subject to simultaneity bias in that the risk of needing acute care or worsening of one's condition may also influence family care use (reverse causality). Failure to address these issues could lead to inconsistent estimates. Depending on the nature of the omitted variables, the inconsistency from simple covariate adjustment could be in either direction. We use instrumental variables estimation to address these biases.

To obtain consistent estimates, we apply an instrumental variables approach to Medicaid claims data for adult enrollees of the Cash and Counseling Demonstration and Evaluation (CCDE) program, described above. Random assignment into the treatment group serves as our instrument for having family involved in the home care received. Thus, we identify the arguably causal effects of interest among individuals who were induced to use more family care as a result of being in the treatment group of the CCDE.

When conducting IV analysis, we use a two-stage residual inclusion (2SRI) technique, the preferred approach when using nonlinear models (Terza et al., 2008). The first-stage 2SRI residual based on all analysis observations is calculated from a probit regression of having family involvement in home care on CCDE treatment status. The first stage equation we estimate is:

$$
\operatorname{Pr}\left(F C_{i, t+9}>0\right)=\phi\left(\alpha+\beta_{1} \text { Treatment }_{i}+\beta_{2} M_{i, t+9}+\beta_{3} X_{i, t}+\sigma_{i}+\varepsilon_{i}\right)
$$

where $F C, M, X$, and $\sigma$ are as defined above. Treatment is an indicator for being randomly assigned to the treatment group as part of the CCDE project. For binary outcomes and duration 
model, the second stage model augments equation (3) and equation (4) with the predicted residual from the first stage (equation 5). For the utilization and expenditure models, the predicted residual is included in both parts of the 2PM. The 95\% confidence intervals of the marginal effects from recombined models are obtained via 1,000 nonparametric bootstrap replicates on the whole analysis sample with percentile method (Efron, 1979).

\section{Results.}

4.1 Descriptive Results. Table 1 presents the prevalence of individual characteristics measured at baseline. Column 1 is for the full sample, while columns 2 and 3 present the descriptive statistics for the CCDE control group and treatment group respectively. The fourth and final column presents the significance of the Pearson test of the differences in the mean between the treatment and control groups.

The baseline characteristics are as expected, given the eligibility criteria for the CCDE. 71 percent of the population is female and over 63 percent of the population is over the age of 65. Approximately one-third of the population is from each of the three states participating in the CCDE. 29 percent of the population is African-American; 21 percent is Hispanic. While over 85

percent of the population is unmarried, at baseline the majority are already receiving some sort of unpaid help, ranging from 60 percent getting help with transportation needs to 83 percent receiving assistance with household or community activities.

Since individuals had to be already receiving Medicaid home care to qualify for the program, the health care needs are relatively high. Cardiovascular problems are prevalent, reported by over one-quarter of the population. Almost one in six reports a musculoskeletal 
issue. While the other conditions are less prevalent, they are still not rare, ranging from 3.4 percent reporting a mental illness to around 10 percent reporting cancer or pulmonary problems. Importantly, illustrating that the random assignment was successful, there is only one statistically significant difference in the characteristics between the treatment and control groups. The control group is slightly less likely to report pulmonary conditions than the treatment group. We include all of these baseline measures in the models as controls.

Additionally, we compare the observable characteristics between treatment and control groups for three subsamples: individuals under age 65; individuals age 65 and older; and individuals living alone (see Table 2). Again, observable characteristics are largely balanced between the treatment and control groups within the sub-samples, with the exception of a two health conditions and a racial category that are statistically different but exhibit no directional pattern.

Table 3 presents the average characteristics of the variables measured 9 months after randomization, by treatment status. The control group has slightly higher utilization for all five utilization outcome measures, although these differences are not statistically significantly different from each other. Similarly, the control group reports worse health outcomes across the board, although, again, the averages between the control and treatment groups are not statistically different from one another.

We know from the CCDE evaluations that we should expect differences between the treatment and control groups in terms of how Medicaid dollars were spent and the hours of paid and unpaid care received (Anderson et al., 2012; Carlson et al., 2007b; Foster et al., 2007) . As anticipated, the treatment group spends significantly more Medicaid dollars on counseling than 
the control group. We also find that the treatment group receives more paid care and fewer unpaid hours of care than the control group.

Importantly, we see that the treatment group is more likely to have family involved in home care than the control group; 82 percent of the treatment group has family involved, while 77 percent of the control group does.

4.2 Instrument validity tests. In addition to the balance of the baseline characteristics between treatment and control groups illustrated in Table 1, our instrumental variable, being randomized to treatment, is highly predictive of whether an individual received family care in addition to agency home care. Our estimates suggest that individuals in the treatment group were 3.8 percentage points $(\mathrm{p}<0.01)$ more likely to have family involved in home care than those in the treatment group. The Chi-squared statistic is 10.14 and significant at the 0.002 level. We are able to reject the null hypothesis that family care is exogenous for Medicaid utilization using the Hausman test for exogeneity (Table 4). Although we do not find statistical evidence of endogeneity for all outcomes based on the Hausman test, we treat family care as endogenous in all models given that we detect endogeneity in conceptually related outcomes.

\subsection{Utilization and Expenditure results. In models that do not control for selection, we find that} there is a modest negative effect of having family involved in care on all utilization and spending measures. These results suggest that, for a given number of hours of care, individuals receiving at least part of that care from family are 4.7 percentage points less likely to use the ER, 6 percentage points less likely to use the hospital, spend 2 fewer days in the hospital over 9 
months, and Medicaid spends $\$ 442$ less over 9 months on these patients compared to the group without any family involved in their home care (Panel A, Table 5).

In the instrumental variable model, the magnitudes of the beneficial effect of family involvement increase dramatically. We find that family involvement in care decreases the likelihood of using the emergency room by 30 percentage points and decreases any hospital utilization by 50 percentage points. The number of inpatient days decreases by 13 days due to having family involved in care. Overall, these utilization changes sum to $\$ 1,370$ saved in the Medicaid program over 9 months, although the spending effect is not statistically significantly different from zero.

4.4 Time until hospitalization results. Without controlling for potential endogeneity bias in the non-IV model, having family members involved in care is associated with a 36 percent lower risk of future hospitalization. With the IV model, having family involved in home care significantly reduced the risk of future hospitalization by 86 percent, which could be interpreted as an almost 11-day delay in hospitalization. Thus, the survival model suggests that under the alternative assumption about the timing of hospitalization, having family involved in home care still significantly postpones subsequent use of inpatient care.

4.5 Health Outcomes. Lower health expenditures and delaying hospital care may not be welfareimproving if they result from lower quality of care. Therefore, we examine the effect of having family involved in care on six health measures measured 9 months after randomization.

Overall, only urinary tract infections and bedsores developing or worsening are negatively and significantly correlated with family involvement in care (Non-IV results, Table 5, 
Panel C). Much like the spending results, when we turn to the IV results, the estimates suggest that family care plays an important causal role in health preservation once the endogeneity of the relationship between health and who provides care is addressed using our instrumental variable approach. For all but one of the health measures, health improves because family is involved in care. Individuals who use family care (as a result of being randomized to the treatment group) have significantly lower rates of urinary tract (42 percentage points) and respiratory infections (39 percentage points), and a lower likelihood of bedsores (30 percentage points), contractures (47 percentage points), or shortness of breath (76 percentage points) developing or worsening. The estimated positive health effects of receiving family care in addition to agency care are sizable.

4.6 Heterogeneity. To explore the relationship between family involvement and health care utilization and spending, we break down the sample by age in Tables 6 and 7, and study individuals living alone in Table $8 .{ }^{5}$ We have data only on Medicaid spending and not Medicare spending; thus, for those over 65, Medicaid expenditures are more likely to be an underestimate of total spending whereas for younger individuals Medicaid claims are more likely to reflect the majority of expenditures. Thus, while some of the younger individuals may also be enrolled in Medicare, we use age 65 as a reasonable cutoff to proxy for reliance on Medicaid only. We examine the effect by living arrangement and disease diagnosis to determine if the response of

\footnotetext{
${ }^{5}$ The randomization does not predict family involvement in care for individuals living with others, thus we do not have a valid instrument for that subsample and we do not present those results.
} 
family involvement in care is more pronounced among particular individuals who could be identified ex ante and where policy could be targeted.

When we cut the sample by age, we find that the treatment induced use of family care among the young individuals the most, with a 5 percentage point increase in family involvement among individuals under age 65, and only a 2.7 percentage point increase for those age 65 and older. We find IV results for the young sample very similar to the overall results: family involvement in care decreases the likelihood of an emergency room visit by 39 percentage points, and decreases any inpatient visit by 51 percentage points. Again, we find significant increases in health, although only in terms of lower likelihood of infections and bedsores. For the elderly sample, the utilization effects are again in line with the total sample results, and we find health improvements only in the likelihood of urinary tract infections.

We find that the policy induced use of family care primarily for individuals living alone with a 3.6 percentage point increase, and had no statistical impact on the likelihood of having family involved in care for individuals already living with others (results not shown). We find that individuals living alone are less likely to go to the hospital (42 ppt) and have fewer hospital days (11 days) due to their family's involvement in their home care. Further, these decreases in utilization lead to (a statistically significant) \$1564 less in Medicaid spending over 9 months. This group also experiences a lower likelihood of infections and bedsores due to their family involvement in their care.

\section{Robustness and Generalizability}

5.1 Robustness. Our main specification includes controls for factors that we know have changed with the CCDE program, namely the amount spent on counselling and hospice, total hours of paid and unpaid help received in order to isolate the causal impact of the change in care 
provision on our outcomes of interest. However, one could argue that receiving family care could also impact these factors, in which case we are including endogenous regressors in our specification. We estimate the models omitting these potentially endogenous regressors, and, as expected, this results in larger impacts of receiving family care on Medicaid utilization, spending, and health (see Table 9). Thus our main specifications provide conservative estimates of the impact of family care on Medicaid utilization by controlling for these additional channels through which the CCDE may have affected outcomes.

5.2 Generalizability. While the CCDE program provides the randomization necessary to achieve causal estimates, the tradeoff is that generalizability is subject to limitations. The three-state sample might not represent the national sample well, because these states might have different inherent factors than other states that made them participate in CCDE. Even within these three states, although the CCDE minimized early refusal rates by enrolling only those eligible Medicaid beneficiaries who knowingly volunteered and consented to randomization, this participating population may not represent the general Medicaid home care users, because only a modest proportion (6\% to $10 \%$ ) of eligible adults voluntarily enrolled in the demonstration. In order to inform the extent of external validity of this study, we compare the CCDE analysis sample with the national population of users of home and community-based services in 2005 on several selected characteristics, as reported by Konetzka et al. (2012).

Table 10 presents this comparison on two samples, those age 65 and older (column 1) and the total population (column 2). One known non-comparability between the CCDE and the Medicaid HCBS total population is that the latter includes a small proportion of children with long-term care needs, while the CCDE population only contains adults. In general, the mean years of age and the percentage of dually eligible are very similar between the two samples. 
However, the CCDE sample includes more women. There are also some discrepancies in racial characteristics, but it is unclear if these differences appear due to differences in categorization or reporting, since the CCDE sample has fewer people in the "other" or "missing” race categories. Overall, most characteristics of CCDE participants are similar to a broader population of Medicaid home care users.

\section{Discussion}

We find that using payment-induced family care decreases inpatient expenditures substantially. This resulting decrease is not attributable to healthier Medicaid beneficiaries being more likely to use family care because we control for non-random selection into using family care. Thus, our estimate can be interpreted causally—on average, family involvement in home care is a substitute to hospital care. Our results show that saving is achieved through lower emergency room and inpatient usage. For people living alone, having family involved in their care leads to Medicaid spending $\$ 1564$ less in the 9 months after randomization.

To assess whether the overall the marginal benefit of family care is positive, we also pursued a clearer understanding of the health impacts of family care to frame the benefits against the cost savings found in the inpatient setting. If hospital care decreases generally, but health outcomes of participants are worse, for example, it may be that family care in the home was of lower quality, in neglecting accessing care for the participant in a timely manner, for example, or by providing lower quality of care. Family care providers are largely untrained, and thus may be unable to provide the same quality of care of trained agency-care providers, leading to worsening health outcomes. Or, families that are induced to care for a loved one because of a payment may be more likely to delay inpatient care, either due to a desire to maximize their payments or not wanting to admit that they need further assistance in providing care. This, too, could lead to 
worsening patient health. In those cases, the welfare effects of decreased expenditures would be ambiguous, because lower spending could be offset by worse outcomes. On the other hand, it may also be that the presence of family caregivers in the hospital leads to the ability to discharge earlier from the hospital, but without any change in patient outcomes, which would make the use of family caregivers potentially welfare-enhancing. Our analysis of six measures of health taken 9 months after randomization indicated that using payment-induced family care in addition to agency-based home care leads to sizable and significantly better health outcomes in all but one of six of the measures available. Together, these findings suggest that the overall marginal net benefit of family care in addition to agency-based home care is positive and sizable. Depending on the cost of the policies themselves, policies to support family caregivers may hold promise in improving outcomes while holding down costs. Furthermore, the cost savings were strongest among those living alone, suggesting that policies to support family care may be most effective if targeted at non-residential caregivers. It is possible that stronger effects would have been found in the older population if total (Medicare plus Medicaid) costs had been available. Further work to discern the mechanisms through which family care leads to these effects, whether there are subpopulations of older individuals who benefit substantially from family care, and the extent to which these results can be generalized to family caregivers who are not paid, would be helpful to guide policy development to improve home care.

Instrumental variables estimates, although enabling causal inference, should be interpreted as a local average treatment effect. That is, the estimate is derived from observations in which the instrument causes exogenous changes in behavior (“compliers”) and may not be applicable to all observations. In our case, the instrumental variables estimate is derived from observations where family care was used because the individual was in the treatment arm of the 
CCDE experiment and thus was allowed to pay family members, but would not have been used had the individual been assigned to the control group. This might be the case, for example, if the payment allowed a family caregiver to allocate time to caregiving that would not have been possible in the absence of payment, perhaps due to competing work demands. Thus, our estimate of the marginal benefit of family care is most useful for policies that might encourage the use of family care by allowing payment and may not be broadly applicable to family care more generally.

Other limitations of this study include its potential inability to generalize beyond the Medicaid population. While Medicaid pays for approximately one-third of LTC expenditures in the U.S., the findings from this population may not be generalizable to the home care population as a whole, especially affluent and private pay home care markets. Further, the data from the CCDE are relatively old and have limitations. For example, measurement of effects is limited to the 9-month window after randomization. While we feel the strong identification stemming from re-use of the randomization to identify the causal relationship outweighs these drawbacks, one must keep these limitations in mind in interpreting our results.

Given current policy interest in shifting resources away from institutional care and into the home among public payers such as Medicaid and the Veterans Affairs Health Care system, and among the disability rights community, our findings have important ramifications for policy. Any policy that encourages home and community-based health care inevitably relies more on family care. This may be because family members are paid, as in the case of the CCDE (and in 25 state Home and Community-Based waiver programs in a non-randomized manner), or because it is cost-prohibitive to extend 24-hour care in the home for Medicaid, making it necessary for informal caregivers to supplement the intensity of care for recipients of long-term 
care in the community. Thus, more careful consideration of the marginal benefits of family care, both in the cost and the quality of care realms, will help properly frame the optimal investment decisions between expanding formal care to meet the needs of individuals with LTC needs versus expanding informal care supports. 


\section{$\underline{\text { References }}$}

Anderson RA, Corazzini K, Porter K, Daily K, McDaniel RR, Jr., Colon-Emeric C. CONNECT for quality: protocol of a cluster randomized controlled trial to improve fall prevention in nursing homes. Implementation science : IS 2012;7; 11.

Arno PS, Levine C, Memmott MM. The economic value of informal caregiving. Health Affairs 1999;18; 182-188.

Baumgarten M, Battista RN, Infante-Rivard C, Hanley JA, Becker R, Gauthier S. The psychological and physical health of family members caring for an elderly person with dementia. Journal of clinical epidemiology 1992;45; 61-70.

Bloom BS, de Pouvourville N, Straus WL. Cost of illness of Alzheimer's disease: how useful are current estimates? Gerontologist 2003;43; 158-164.

Brookes S, Whitley E, Peters T, Mulheran P, Egger M, Smith G. Subgroup analyses in randomlized controlled trials: quantifying the risks of false-positives and false-negatives. Health Technology Assessment (Winchester, England) 2001;5; 1-56.

Brown RS, Dale SB, Brown RS, Dale SB. The research design and methodological issues for the Cash and Counseling Evaluation. Health services research 2007;42; 414-445.

Carlson B, Foster L, Dale S, Brown R. Effects of Cash and Counseling on Personal Care and Well-being. Health services research 2007a;42; 467-487.

Carlson BL, Foster L, Dale SB, Brown R. Effects of Cash and Counseling on personal care and well-being. Health services research 2007b;42; 467-487.

CDC. 2003. Public health and aging: trends in aging--United States and worldwide. (Ed)^(Eds), Morbidity and Mortality Weekly Report, vol. 52. 2003.

Charles KK, Sevak P. Can family caregiving substitute for nursing home care? Journal of health economics 2005;24; 1174-1190. 
Christakis NA, Allison PD. Mortality after the hospitalization of a spouse. The New England journal of medicine 2006;354; 719-730.

Clyburn LD, Stones MJ, Hadjistavropoulos T, Tuokko H. Predicting caregiver burden and depression in Alzheimer's disease. Journals of Gerontology, Series B, Psychological Sciences and Social Sciences 2000;55; S2-13.

Coe NB, Van Houtven CH. Caring for mom and neglecting yourself? The health effects of caring for an elderly parent. Health economics 2009;18; 991-1010.

Dale SB, Brown RS. How does Cash and Counseling affect costs? Health services research 2007;42; 488-509.

Doty P, Mahoney KJ, Simon-Rusinowitz L. Designing the Cash and Counseling Demonstration and Evaluation. Health services research 2007;42; 378-396.

Efron B. Bootstrap Methods: Another Look at the Jackknife. The Annals of Statistics 1979;7; 126.

Foster L, Dale SB, Brown R. How caregivers and workers fared in Cash and Counseling. Health services research 2007;42; 510-532.

Genworth. 2016. Compare Long Term Care Costs Across the United States. In: Genworth $(E d)^{\wedge}($ Eds), Annual Median Cost of Long Term Care in the Nation. 2016.

Greene V. Substitution between formally and informally provided care for the impaired elderly in the community. Medical care 1983;21; 609-619.

Guo J, Konetzka RT, Manning W. The causal effects of home care use on institutional long-term care utilization and expenditures. Health Economics 2015;24(S1); 4-17. 
Haley WE, LaMonde LA, Han B, Burton AM, Schonwetter R. Predictors of depression and life satisfaction among spousal caregivers in hospice: application of a stress process model. Journal of Palliative Medicine 2003;6; 215-224.

Haley WE, LaMonde LA, Han B, Narramore S, Schonwetter R. Family caregiving in hospice: effects on psychological and health functioning among spousal caregivers of hospice patients with lung cancer or dementia. Hosp J 2001;15; 1-18.

Harrow BS, Tennstedt SL, McKinlay JB. How costly is it to care for disabled elders in a community setting. The Gerontologist 1995;35; 803-813.

Johnson RW, Toohey D, Wiener JM. Meeting the Long-Term Care Needs of the Baby Boomers: How Changing Families will Affect Paid Helpers and Institutions. The Retirement Project Discussion Paper Series 2007.

Kiecolt-Glaser JK, Dura JR, Speicher CE, Trask OJ, Glaser R. Spousal caregivers of dementia victims: longitudinal changes in immunity and health. Psychosomatic Medicine 1991;53; 345-362.

King AC, Oka RK, Young DR. Ambulatory blood pressure and heart rate responses to the stress of work and caregiving in older women. Journal of Gerontology 1994;49; M239-245.

Konetzka RT. The hidden costs of rebalancing long-term care. Health services research 2014;49; 771-777.

Konetzka RT, Karon SL, Potter DE. Users of medicaid home and community-based services are especially vulnerable to costly avoidable hospital admissions. Health affairs (Project Hope) 2012;31; 1167-1175.

Langa KM, Chernew ME, Kabeto MU, Herzog AR, Ofstedal MB, Willis RJ, Wallace RB, Mucha LM, Straus WL, Fendrick AM. National estimates of the quantity and cost of 
informal caregiving for the elderly with dementia. Journal of general internal medicine 2001;16; 770-778.

Lo Sasso AT, Johnson RW. Does informal care from adult children reduce nursing home admissions for the elderly? Inquiry 2002;39; 279-297.

McCullagh P, Nelder J. Generalized Linear Modelss. Chapman and Hall: UK; 1989.

Morrow-Howell N, Proctor E, Dore P. Adequacy of care: The concept and its measurement. Research on Social Work Practice 1998;8; 86-102.

Morrow-Howell N, Proctor E, Rosario P. How much is enough? Perspectives of care recipients and professionals on the sufficiency of in-home care. Gerontologist 2001;41; 723-732.

Navaie-Waliser M, Feldman PH, Gould DA, Levine C, Kuerbis AN, Donelan K. When the caregiver needs care: the plight of vulnerable caregivers. American journal of public health 2002;92; 409-413.

O'Brien E. 2005. Long-term care: Understanding Medicaid's role for the elderly and disabled. (Ed)^(Eds). Kaiser Commission on Medicaid and the Uninsured; 2005.

O'Shaughnessy CV. 2013. National Spending for Long-Term Services and Supports (LTSS), 2011. (Ed)^(Eds), The Basics. National Health Policy Forum: Washington, D.C.; 2013.

Schulz R, Beach SR. Caregiving as a risk factor for mortality: the Caregiver Health Effects Study. Journal of the Amercian Medical Association 1999;282; 2215-2219.

Schulz R, Martire LM. Family caregiving of persons with dementia: prevalence, health effects, and support strategies. American Journal of Geriatric Psychiatry 2004;12; 240-249.

Schulz R, Mendelsohn AB, Haley WE, Mahoney D, Allen RS, Zhang S, Thompson L, Belle SH. End-of-life care and the effects of bereavement on family caregivers of persons with dementia. New England Journal of Medicine 2003;349; 1936-1942. 
Schulz R, O'Brien AT, Bookwala J, Fleissner K. Psychiatric and physical morbidity effects of dementia caregiving: prevalence, correlates, and causes. Gerontologist 1995;35; 771-791.

Skinner E, Steinwach D, Handley K, Lehman A, Fahey M, Lyles C. Met and unmet needs for assistance and quality of life for people with severe and persistent mental disorders. Mental Health Services Research 1999;1; 109-118.

Skira M. Dynamic Wage and Employment Effects of Elder Parent Care. International Economic Review In press.

Small GW, McDonnell DD, Brooks RL, Papadopoulos G. The impact of symptom severity on the cost of Alzheimer's disease. Journal of the American Geriatric Society 2002;50; 321327.

Spillman BC, Pezzin LE. Potential and active family caregivers: changing networks and the "sandwich generation". Milbank Quarterly 2000;78; 339-347.

Stone R, Cafferata GL, Sangl J. Caregivers of the Frail Elderly: A National Profile. The Gerontologist 1987;27; 616-626.

Terza JV, Basu A, Rathouz PJ. Two-stage residual inclusion estimation: addressing endogeneity in health econometric modeling. Journal of health economics 2008;27; 531-543.

Van Houtven C, Norton E. Informal Care and Elderly Health Care Use. Journal of health economics 2004;23; 1159-1180.

Van Houtven C, Norton E. Informal Care and Medicare Expenditures:Testing for Heterogeneous Treatment Effects. Journal of health economics 2008;27; 134-156.

Vitaliano PP. Physiological and physical concomitants of caregiving: introduction. Annals of Behavioral Medicine 1997;19; 75-77. 
Vitaliano PP, Zhang J, Scanlan JM. Is caregiving hazardous to one's physical health? A metaanalysis. Psychological Bulletin 2003;129; 946-972.

Weissert W, Chernew M, Hirth R. Titrating versus targeting home care services to frail elderly clients: an application of agency theory and cost-benefit analysis to home care policy. Journal of aging and health 2003;15; 99-123. 
Table 1: Descriptive statistics at Baseline

\begin{tabular}{|c|c|c|c|c|}
\hline Baseline Status (\%) & $\begin{array}{c}\text { Total } \\
\text { Sample }\end{array}$ & Control & Treatment & $\begin{array}{c}\text { Pearso } \\
\text { n test }\end{array}$ \\
\hline $\mathrm{N}$ & 4990 & 2492 & 2498 & \\
\hline \multicolumn{5}{|l|}{ Gender } \\
\hline Female & 70.620 & $70.4 \%$ & $70.9 \%$ & \\
\hline \multicolumn{5}{|l|}{ Age } \\
\hline Age 18-64 & 43.484 & $43.7 \%$ & $43.2 \%$ & \\
\hline Age $65-79$ & 37.896 & $37.3 \%$ & $38.5 \%$ & \\
\hline Age $80+$ & 25.559 & $26.2 \%$ & $24.9 \%$ & \\
\hline \multicolumn{5}{|l|}{ State } \\
\hline Arkansas & 34.530 & $34.8 \%$ & $34.3 \%$ & \\
\hline Florida & 33.470 & $33.1 \%$ & $33.9 \%$ & \\
\hline New Jersey & 31.995 & $32.2 \%$ & $31.8 \%$ & \\
\hline \multicolumn{5}{|l|}{ Race \& Ethnicity } \\
\hline Black & 29.040 & $29.0 \%$ & $29.1 \%$ & \\
\hline Hispanic & 21.214 & $21.7 \%$ & $20.8 \%$ & \\
\hline \multicolumn{5}{|l|}{ Potential Informal Care Resources } \\
\hline Married & 14.976 & $14.5 \%$ & $15.4 \%$ & \\
\hline Unpaid help: transportation & $60.3 \%$ & $60.7 \%$ & $59.8 \%$ & \\
\hline Unpaid help: house/comm activities & $82.5 \%$ & $83.2 \%$ & $81.8 \%$ & \\
\hline \multicolumn{5}{|l|}{ Health Status \& Disease History } \\
\hline Skeletal & 16.3 & $17.1 \%$ & $15.5 \%$ & \\
\hline Skin high cost & 7.8 & $7.7 \%$ & $7.9 \%$ & \\
\hline Cancer & 10.1 & $10.1 \%$ & $10.2 \%$ & \\
\hline Cardiovascular & 27.1 & $26.2 \%$ & $27.9 \%$ & \\
\hline Gastrointestinal & 6.8 & $6.5 \%$ & $7.1 \%$ & \\
\hline Hematological & 6.4 & $6.1 \%$ & $6.7 \%$ & \\
\hline Psychiatric & 3.4 & $3.5 \%$ & $3.3 \%$ & \\
\hline Pulmonary & 9.8 & $8.8 \%$ & $10.9 \%$ & $* *$ \\
\hline
\end{tabular}

Note: The significance levels of $1 \%, 5 \%$, and $10 \%$ are denoted by $* * *, * *$, and * respectively. 
Table 2. Sub-sample Descriptive Statistics at Baseline

\begin{tabular}{|c|c|c|c|c|c|c|c|c|c|}
\hline & \multicolumn{3}{|c|}{ Age $<65$} & \multicolumn{3}{|c|}{ Age $>=65$} & \multicolumn{3}{|c|}{ Live Alone } \\
\hline $\begin{array}{l}\text { Baseline Status } \\
(\%)\end{array}$ & $\begin{array}{c}\text { Cont } \\
\text { rol }\end{array}$ & $\begin{array}{l}\text { Treat } \\
\text { ment }\end{array}$ & $\begin{array}{l}\text { Pear } \\
\text { son } \\
\text { test }\end{array}$ & $\begin{array}{c}\text { Cont } \\
\text { rol }\end{array}$ & $\begin{array}{l}\text { Treat } \\
\text { ment }\end{array}$ & $\begin{array}{l}\text { Pear } \\
\text { son } \\
\text { test }\end{array}$ & $\begin{array}{c}\text { Cont } \\
\text { rol }\end{array}$ & $\begin{array}{l}\text { Treat } \\
\text { ment }\end{array}$ & $\begin{array}{l}\text { Pear } \\
\text { son } \\
\text { test }\end{array}$ \\
\hline $\mathrm{N}$ & 1127 & 1116 & & 1365 & 1364 & & 1748 & 1760 & \\
\hline Gender & & & & & & & & & \\
\hline Female & 58.8 & 57.3 & & 79.9 & 82.0 & & 68.0 & 67.7 & \\
\hline Age & & & & & & & & & \\
\hline Age 18-64 & 49.2 & 47.4 & & 0 & 0 & & 28.8 & 27.3 & \\
\hline Age 65-79 & 0 & 0 & & 52.1 & 54.8 & & 25.8 & 28.4 & \\
\hline Age 80+ & 0 & 0 & & 47.9 & 45.2 & & 27.5 & 26.5 & \\
\hline State & & & & & & & & & \\
\hline Arkansas & 22.7 & 22.6 & & 44.7 & 43.9 & & 32.7 & 32.0 & \\
\hline Florida & 43.2 & 44.3 & & 24.7 & 25.4 & & 38.0 & 39.0 & \\
\hline New Jersey & 34.1 & 33.2 & & 30.6 & 30.7 & & 29.2 & 29.0 & \\
\hline Race \& I & thnicity & & & & & & & & \\
\hline Black & $28.7^{\circ}$ & 26.4 & & 29.2 & 31.2 & & 29.6 & 28.5 & \\
\hline Hispanic & 20.5 & 19.3 & & 22.6 & 22.0 & * & 23.1 & 22.5 & \\
\hline Potential Info & mal Ca & e Resot & ces & & & & & & \\
\hline Married & 10.6 & 12.5 & & 17.7 & 17.8 & & 17.8 & 19.2 & \\
\hline $\begin{array}{l}\text { Unpaid help: } \\
\text { transportation }\end{array}$ & 67.8 & 66.9 & & 54.9 & 54.1 & & 65.6 & 64.4 & \\
\hline $\begin{array}{l}\text { Unpaid help: } \\
\text { house/comm } \\
\text { activities }\end{array}$ & 83.7 & 82.9 & & 82.8 & 81.0 & & 92.5 & 91.5 & \\
\hline Health Sta & \& Dise & se Hist & & & & & & & \\
\hline Skeletal & 13.5 & 13.0 & & 20.0 & 17.6 & & 14.0 & 14.4 & \\
\hline $\begin{array}{l}\text { Skin high } \\
\text { cost }\end{array}$ & 7.0 & 6.8 & & 8.2 & 8.9 & & 8.1 & 8.1 & \\
\hline Cancer & 5.4 & 5.7 & & 13.9 & 13.8 & & 8.9 & 8.6 & \\
\hline Cardiovascular & 12.3 & 13.7 & & 37.7 & 39.5 & & 23.6 & 26.1 & * \\
\hline Gastrointestinal & 6.8 & 6.3 & & 6.1 & 7.7 & & 6.5 & 6.5 & \\
\hline Hematc & 4.6 & 5.3 & & 7.3 & 7.9 & & 5.7 & 6.1 & \\
\hline Psychiatric & 5.2 & 5.1 & & 2.0 & 1.8 & & 3.0 & 3.1 & \\
\hline Pulmonary & 7.0 & 9.5 & $* *$ & 10.2 & 12.0 & & 8.5 & 9.9 & \\
\hline
\end{tabular}

Note: The significance levels of $1 \%, 5 \%$, and $10 \%$ are denoted by ***, **, and * respectively. 
Figure 3: Descriptive Statistics: After Randomization

\begin{tabular}{|c|c|c|c|c|}
\hline \multirow[b]{2}{*}{ Dependent Variables } & \multicolumn{2}{|c|}{$\begin{array}{c}\text { Control } \\
(\mathrm{N}=2492)\end{array}$} & \multicolumn{2}{|c|}{$\begin{array}{l}\text { Treatment } \\
(\mathrm{N}=2480)\end{array}$} \\
\hline & & & & \\
\hline \multicolumn{5}{|l|}{ Utilization and Spending } \\
\hline Any ER Visit & 0.22 & $(0.41)$ & 0.20 & $(0.40)$ \\
\hline Any Inpatient Spending & 0.30 & $(0.46)$ & 0.29 & $(0.46)$ \\
\hline Medicaid Inpatient Days & 4.75 & $(13.12)$ & 4.42 & $(12.02)$ \\
\hline Months with Inpatient Spending & 0.46 & $(0.94)$ & 0.44 & $(0.92)$ \\
\hline Medicaid Inpatient Spending & 896.09 & $(4986.71)$ & 822.49 & $(4034.90)$ \\
\hline \multicolumn{5}{|l|}{ Duration } \\
\hline Time until hospitalization (month) & 7.56 & & 7.57 & \\
\hline \multicolumn{5}{|l|}{ Health Outcomes } \\
\hline Current Health is Poor Relative to Peers & 0.41 & $(0.49)$ & 0.39 & $(0.49)$ \\
\hline Had a Urinary Tract Infection & 0.18 & $(0.38)$ & 0.16 & $(0.37)$ \\
\hline Had a Respiratory Infection & 0.25 & $(0.44)$ & 0.24 & $(0.42)$ \\
\hline Bedsores Developed or Worsened & 0.08 & $(0.27)$ & 0.06 & $(0.25)$ \\
\hline Contractures Developed or Worsened & 0.21 & $(0.41)$ & 0.18 & $(0.38)$ \\
\hline Shortness of Breath Developed or Worsened & 0.32 & $(0.47)$ & 0.27 & $(0.45)$ \\
\hline \multicolumn{5}{|l|}{ Independent Variable } \\
\hline Family Involvement in care & 76.6 & $(42.3)$ & 82.1 & $(38.3)$ \\
\hline \multicolumn{5}{|c|}{ Control Variables: Other \$ \& care hours during 9 months } \\
\hline Counseling \$ & 88.31 & $(266.87)$ & 1704.63 & (3126.92) \\
\hline Hospice \$ & 14.32 & $(507.54)$ & 40.10 & $(1051.27)$ \\
\hline Total unpaid home care & 124.79 & $(112.82)$ & 115.16 & $(105.22)$ \\
\hline Total paid home care & 28.46 & $(33.07)$ & 33.61 & (29.34) \\
\hline
\end{tabular}


Table 4. Specification tests for the instrumental variable $(\mathrm{N}=4972)$

\begin{tabular}{|c|c|c|c|c|c|c|}
\hline \multirow[t]{2}{*}{ Dependent Variable } & \multicolumn{2}{|c|}{$\begin{array}{c}\text { Effect of the } \\
\text { Instrument } \\
\text { (Randomization } \\
\text { into the } \\
\text { Treatment } \\
\text { Group) }\end{array}$} & \multicolumn{2}{|c|}{$\begin{array}{l}\text { Strength of the } \\
\text { Instruments }\end{array}$} & \multicolumn{2}{|c|}{$\begin{array}{c}\text { Hausman } \\
\text { exogeneity test - } \\
\text { regression form }\end{array}$} \\
\hline & $\begin{array}{c}\text { Marginal } \\
\text { Effect }\end{array}$ & $\begin{array}{c}\mathrm{p}^{-} \\
\text {value }\end{array}$ & $\begin{array}{c}\text { statistics } \\
\left(\chi_{1}^{2}\right)\end{array}$ & $\begin{array}{c}\mathrm{p}- \\
\text { value }\end{array}$ & $\begin{array}{l}\text { Statistics } \\
\left(\chi_{2}^{2}\right)\end{array}$ & $\begin{array}{c}\mathrm{p}- \\
\text { value }\end{array}$ \\
\hline \multicolumn{7}{|l|}{ First Stage } \\
\hline Family Involvement in Care & 0.0377 & 0.001 & 10.14 & 0.0015 & & \\
\hline \multicolumn{7}{|l|}{ Second Stage } \\
\hline Any ER & & & & & 4.49 & 0.034 \\
\hline Any Inpatient Days & & & & & 8.86 & 0.0029 \\
\hline Inpatient Days & & & & & 9.47 & 0.0021 \\
\hline Months with Inpatient Spending & & & & & 10.67 & 0.0011 \\
\hline Any Inpatient Spending & & & & & 9.99 & 0.0016 \\
\hline Inpatient Spending & & & & & 1.74 & 0.1874 \\
\hline Time until Hospitalization & & & & & 6.53 & 0.0106 \\
\hline $\begin{array}{l}\text { Current Health is Poor Relative } \\
\text { to Peers }\end{array}$ & & & & & 1.34 & 0.2469 \\
\hline Had a Urinary Tract Infection & & & & & 12.99 & 0.0003 \\
\hline Had a Respiratory Infection & & & & & 9.68 & 0.0019 \\
\hline $\begin{array}{l}\text { Bedsores Developed or } \\
\text { Worsened }\end{array}$ & & & & & 4.01 & 0.0453 \\
\hline $\begin{array}{l}\text { Contractures Developed or } \\
\text { Worsened }\end{array}$ & & & & & 0.01 & 0.9125 \\
\hline $\begin{array}{l}\text { Shortness of Breath Developed } \\
\text { or Worsened }\end{array}$ & & & & & 2.59 & 0.1077 \\
\hline
\end{tabular}


Table 5. Marginal effects of receiving family care on acute care utilization and spending

\begin{tabular}{|c|c|c|c|c|}
\hline & \multicolumn{2}{|c|}{ Non-IV Model } & \multicolumn{2}{|c|}{ IV Model } \\
\hline & \multirow{2}{*}{$\begin{array}{l}\text { Marginal } \\
\text { Effect }\end{array}$} & & \multicolumn{2}{|l|}{ Marginal } \\
\hline & & $95 \% \mathrm{CI}$ & Effect & $95 \%$ CI \\
\hline $\begin{array}{l}\text { Family Involvement } \\
\text { (First Stage) }\end{array}$ & & & $0.0377 * * *$ & {$[0.0144,0.0609]$} \\
\hline Utilization & & & & \\
\hline Any ER & $-0.0523 * * *$ & {$[-0.0791,-0.0254]$} & $-0.298 * *$ & {$[-0.577,-0.0199]$} \\
\hline Any Inpatient Days & $-0.0665 * * *$ & {$[-0.0966,-0.0365]$} & $-0.500 * * *$ & {$[-0.831,-0.169]$} \\
\hline Inpatient Days & $-2.431^{* * *}$ & {$[-3.222,-1.641]$} & $-12.72^{* * *}$ & {$[-20.85,-4.593]$} \\
\hline Any Medicaid Inpatient \$ & $-0.0612 * * *$ & {$[-0.0905,-0.0319]$} & $-0.536 * * *$ & {$[-0.859,-0.213]$} \\
\hline \# months with Inpatient \$ & $-0.154^{* * *}$ & {$[-0.214,-0.0940]$} & $-1.012 * * *$ & {$[-1.641,-0.382]$} \\
\hline Medicaid Inpatient \$ & $-519.1 * * *$ & {$[-753.2,-285.1]$} & -1368.3 & {$[-3413.2,676.6]$} \\
\hline Duration & & & & \\
\hline Time until Hospitalization & -.2734 & {$[-.3981,-.1486]$} & $-1.994 * * *$ & {$[-3.319,-.669]$} \\
\hline Health Outcomes & & & & \\
\hline Health Poor & -0.0395 & {$[-0.0911,0.0120]$} & -0.222 & {$[-0.594,0.150]$} \\
\hline Urinary Tract Infection & $-0.0550 * * *$ & {$[-0.0943,-0.0158]$} & $-0.521 * * *$ & {$[-0.806,-0.237]$} \\
\hline Respiratory Infection & -0.0274 & {$[-0.0733,0.0184]$} & $-0.501 * * *$ & $\begin{array}{c}{[-0.817,-0.185]} \\
{[-0.400,-}\end{array}$ \\
\hline Bedsores & $-0.0565 * * *$ & {$[-0.0818,-0.0312]$} & $-0.202^{* *}$ & $0.00336]$ \\
\hline Contractures & -0.0122 & {$[-0.0567,0.0323]$} & 0.0198 & {$[-0.292,0.332]$} \\
\hline Shortness of Breath & -0.00911 & {$[-0.0554,0.0371]$} & -0.279 & {$[-0.612,0.0550]$} \\
\hline
\end{tabular}


Table 6: Marginal effects of receiving family care: Age $<65$

\begin{tabular}{|c|c|c|c|c|}
\hline & \multicolumn{2}{|c|}{ Non-IV Model } & \multicolumn{2}{|c|}{ IV Model } \\
\hline & $\begin{array}{l}\text { Marginal } \\
\text { Effect }\end{array}$ & $95 \% \mathrm{CI}$ & $\begin{array}{l}\text { Marginal } \\
\text { Effect }\end{array}$ & $95 \% \mathrm{CI}$ \\
\hline $\begin{array}{l}\text { Family Involvement } \\
\text { (First Stage) }\end{array}$ & & & $0.0501^{* * *}$ & {$[0.0158,0.0844]$} \\
\hline Utilization & & & & \\
\hline Any ER & -0.0293 & {$[-0.0645,0.00588]$} & $-0.386 * *$ & {$[-0.708,-0.0636]$} \\
\hline Any Inpatient Days & $-0.0519 * * *$ & {$[-0.0904,-0.0133]$} & $-0.508^{* * *}$ & {$[-0.876,-0.140]$} \\
\hline Inpatient Days & $-1.239 * *$ & {$[-2.321,-0.158]$} & $-9.538 * *$ & {$[-18.38,-0.695]$} \\
\hline Any Medicaid Inpatient \$ & $-0.0449 * *$ & {$[-0.0826,-0.00712]$} & $-0.564 * * *$ & {$[-0.922,-0.206]$} \\
\hline \# months with Inpatient \$ & $-0.0961 * *$ & {$[-0.181,-0.0109]$} & $-1.033 * * *$ & {$[-1.793,-0.273]$} \\
\hline Medicaid Inpatient \$ & $-846.4 * * *$ & {$[-1373.1,-319.7]$} & -1553.8 & {$[-5375.7,2268.2]$} \\
\hline \multicolumn{5}{|l|}{ Duration } \\
\hline Time until Hospitalization & $-0.330 * * *$ & {$[-0.546,-0.114]$} & $-3.500 * * *$ & {$[-5.675,-1.326]$} \\
\hline \multicolumn{5}{|l|}{ Health Outcomes } \\
\hline Health Poor & -0.0209 & {$[-0.0963,0.0546]$} & -0.145 & {$[-0.590,0.300]$} \\
\hline Urinary Tract Infection & -0.0120 & {$[-0.0703,0.0462]$} & $-0.494 * * *$ & {$[-0.851,-0.137]$} \\
\hline Respiratory Infection & -0.0142 & {$[-0.0869,0.0586]$} & $-0.507 * *$ & {$[-0.929,-0.0843]$} \\
\hline Bedsores & $-0.0444 * *$ & {$[-0.0857,-0.00315]$} & $-0.363 * * *$ & {$[-0.638,-0.0889]$} \\
\hline Contractures & 0.0453 & {$[-0.0275,0.118]$} & -0.152 & {$[-0.555,0.251]$} \\
\hline Shortness of Breath & 0.0217 & {$[-0.0453,0.0887]$} & -0.315 & {$[-0.708,0.0775]$} \\
\hline
\end{tabular}


Table 7: Marginal effects of receiving family care: Age $>=65$

\begin{tabular}{|c|c|c|c|c|}
\hline & \multicolumn{2}{|c|}{ Non-IV Model } & \multicolumn{2}{|c|}{ IV Model } \\
\hline & $\begin{array}{l}\text { Marginal } \\
\text { Effect }\end{array}$ & $95 \% \mathrm{CI}$ & $\begin{array}{l}\text { Marginal } \\
\text { Effect }\end{array}$ & $95 \% \mathrm{CI}$ \\
\hline $\begin{array}{l}\text { Family Involvement } \\
\text { (First Stage) }\end{array}$ & & & $0.0271 *$ & {$[-0.00433,0.0585]$} \\
\hline Utilization & & & & \\
\hline Any ER & $-0.0718 * * *$ & {$[-0.111,-0.0327]$} & -0.225 & {$[-0.637,0.187]$} \\
\hline Any Inpatient Days & $-0.0745 * * *$ & {$[-0.119,-0.0302]$} & $-0.521 * *$ & {$[-1.003,-0.0386]$} \\
\hline Inpatient Days & $-3.497 * * *$ & {$[-4.597,-2.396]$} & $-12.56 * *$ & {$[-24.95,-0.171]$} \\
\hline Any Medicaid Inpatient \$ & $-0.0706 * * *$ & {$[-0.114,-0.0274]$} & $-0.504 * *$ & {$[-0.976,-0.0331]$} \\
\hline \# months with Inpatient \$ & $-0.197 * * *$ & {$[-0.280,-0.114]$} & $-0.819 *$ & {$[-1.687,0.0504]$} \\
\hline Medicaid Inpatient \$ & $-222.2 * * *$ & {$[-354.9,-89.62]$} & -138.6 & {$[-1490.1,1212.8]$} \\
\hline \multicolumn{5}{|l|}{ Duration } \\
\hline Time until Hospitalization & $-0.233 * * *$ & {$[-0.386,-0.079]$} & -1.052 & {$[-2.738,0.634]$} \\
\hline \multicolumn{5}{|l|}{ Health Outcomes } \\
\hline Health Poor & $-0.0605 *$ & {$[-0.131,0.0102]$} & -0.377 & {$[-0.913,0.159]$} \\
\hline Urinary Tract Infection & $-0.0873 * * *$ & {$[-0.141,-0.0335]$} & $-0.526 * * *$ & {$[-0.921,-0.131]$} \\
\hline Respiratory Infection & -0.0355 & {$[-0.0955,0.0245]$} & -0.337 & {$[-0.774,0.101]$} \\
\hline Bedsores & $-0.0739 * * *$ & {$[-0.106,-0.0414]$} & -0.0715 & {$[-0.323,0.180]$} \\
\hline Contractures & $-0.0590 * *$ & {$[-0.116,-0.00228]$} & 0.195 & {$[-0.232,0.623]$} \\
\hline Shortness of Breath & -0.0341 & {$[-0.0980,0.0298]$} & -0.0240 & {$[-0.532,0.484]$} \\
\hline
\end{tabular}

Note: The significance levels of $1 \%, 5 \%$, and $10 \%$ are denoted by $* * *, * *$, and $*$ respectively. 
Table 8: Marginal effects of receiving family care: Live Alone

\begin{tabular}{|c|c|c|c|c|}
\hline & \multicolumn{2}{|c|}{ Non-IV Model } & \multicolumn{2}{|c|}{ IV Model } \\
\hline & \multirow{2}{*}{$\begin{array}{l}\text { Marginal } \\
\text { Effect }\end{array}$} & & \multicolumn{2}{|l|}{ Marginal } \\
\hline & & $95 \%$ CI & Effect & $95 \% \mathrm{CI}$ \\
\hline $\begin{array}{l}\text { Family Involvement } \\
\text { (First Stage) }\end{array}$ & & & $0.0362^{* * *}$ & {$[0.0107,0.0616]$} \\
\hline Utilization & & & & \\
\hline Any ER & $-0.0635^{* * *}$ & {$[-0.0959,-0.0310]$} & -0.144 & {$[-0.374,0.0857]$} \\
\hline Any Inpatient Days & $-0.0825 * * *$ & {$[-0.119,-0.0458]$} & $-0.417 * * *$ & {$[-0.685,-0.148]$} \\
\hline Inpatient Days & $-2.492 * * *$ & {$[-3.356,-1.628]$} & $-11.32 * * *$ & {$[-17.65,-4.992]$} \\
\hline Any Medicaid Inpatient \$ & $-0.0784 * * *$ & {$[-0.114,-0.0429]$} & $-0.432 * * *$ & {$[-0.693,-0.172]$} \\
\hline \# months with Inpatient \$ & $-0.194 * * *$ & {$[-0.267,-0.121]$} & $-0.881^{* * *}$ & {$[-1.389,-0.373]$} \\
\hline Medicaid Inpatient \$ & $-552.3^{* * *}$ & {$[-828.7,-275.9]$} & $-1563.8^{* *}$ & {$[-3050.3,-77.29]$} \\
\hline Duration & & & & \\
\hline Time until Hospitalization & $-.355 * * *$ & {$[-0.518,-0.193]$} & $-2.803^{* * *}$ & {$[-4.508,-1.098]$} \\
\hline Health Outcomes & & & & \\
\hline Health Poor & $-0.107 * * *$ & {$[-0.184,-0.0302]$} & -0.153 & {$[-0.468,0.161]$} \\
\hline Urinary Tract Infection & $-0.103 * * *$ & {$[-0.157,-0.0493]$} & $-0.426 * * *$ & {$[-0.648,-0.204]$} \\
\hline Respiratory Infection & -0.0508 & {$[-0.120,0.0188]$} & $-0.341 * *$ & {$[-0.611,-0.0717]$} \\
\hline Bedsores & $-0.0717 * * *$ & {$[-0.105,-0.0383]$} & $-0.133 *$ & {$[-0.280,0.0139]$} \\
\hline Contractures & $-0.0596 *$ & {$[-0.122,0.00304]$} & -0.00530 & {$[-0.259,0.248]$} \\
\hline Shortness of Breath & -0.0294 & {$[-0.0975,0.0388]$} & -0.108 & {$[-0.375,0.159]$} \\
\hline
\end{tabular}

Note: The significance levels of $1 \%, 5 \%$, and $10 \%$ are denoted by ***, **, and * respectively. 
Table 9: Marginal effects of receiving family care without additional controls

\begin{tabular}{|c|c|c|c|c|}
\hline & \multicolumn{2}{|c|}{ Non-IV Model } & \multicolumn{2}{|c|}{ IV Model } \\
\hline & \multirow[t]{2}{*}{$\begin{array}{c}\text { Marginal } \\
\text { Effect }\end{array}$} & \multicolumn{3}{|c|}{$\begin{array}{c}\text { Marginal } \\
\text { Effect }\end{array}$} \\
\hline $\begin{array}{l}\text { Family Involvement } \\
\text { (First Stage) }\end{array}$ & & & $0.0585 * * *$ & {$[0.0368,0.0802]$} \\
\hline \multicolumn{5}{|l|}{ Utilization } \\
\hline Any ER & $-0.0473 * * *$ & {$[-0.0736,-0.0210]$} & -0.285 & {$[-0.625,0.0547]$} \\
\hline Any Inpatient Days & $-0.0621 * * *$ & {$[-0.0917,-0.0325]$} & -0.257 & {$[-0.644,0.130]$} \\
\hline Inpatient Days & $-2.250 * * *$ & {$[-3.013,-1.486]$} & $-10.57 * *$ & {$[-19.90,-1.233]$} \\
\hline Any Medicaid Inpatient \$ & $-0.0570 * * *$ & {$[-0.0858,-0.0282]$} & $-0.317 *$ & {$[-0.693,0.0590]$} \\
\hline \# months with Inpatient \$ & $-0.154 * * *$ & {$[-0.214,-0.0940]$} & -0.622 & {$[-1.372,0.129]$} \\
\hline Medicaid Inpatient \$ & $-441.5^{* * *}$ & {$[-668.3,-214.8]$} & $-2256.0 *$ & {$[-4829.7,317.7]$} \\
\hline \multicolumn{5}{|l|}{ Duration } \\
\hline Time until Hospitalization & $-0.294 * * *$ & {$[-0.412,-0.176]$} & $-0.815^{* * *}$ & {$[-1.201,-0.428]$} \\
\hline \multicolumn{5}{|l|}{ Health Outcomes } \\
\hline Health Poor & -0.0153 & {$[-0.0650,0.0344]$} & -0.243 & {$[-0.698,0.213]$} \\
\hline Urinary Tract Infection & $-0.0498 * * *$ & {$[-0.0876,-0.0119]$} & $-0.419 * *$ & {$[-0.778,-0.0603]$} \\
\hline Respiratory Infection & -0.0242 & {$[-0.0687,0.0202]$} & $-0.392 *$ & {$[-0.796,0.0125]$} \\
\hline Bedsores & $-0.0487 * * *$ & {$[-0.0728,-0.0247]$} & $-0.302 * *$ & {$[-0.547,-0.0569]$} \\
\hline Contractures & -0.00322 & {$[-0.0464,0.0400]$} & $-0.469 * *$ & {$[-0.856,-0.0828]$} \\
\hline Shortness of Breath & -0.0297 & {$[-0.0749,0.0154]$} & $-0.758 * * *$ & {$[-1.171,-0.344]$} \\
\hline
\end{tabular}


Table 10: Selected characteristics of Cash \& Counseling Demonstration enrollees

\begin{tabular}{l|cc|cc}
\hline \multirow{2}{*}{$\begin{array}{l}\text { Selected } \\
\text { characteristics }\end{array}$} & $\begin{array}{c}|c| \\
\text { Age 65 or older } \\
\text { population }\end{array}$ & $\begin{array}{c}\text { CCDE } \\
\text { population }\end{array}$ & $\begin{array}{c}2005 \text { HCBS } \\
\text { population }\end{array}$ & $\begin{array}{c}\text { CCDE } \\
\text { population }\end{array}$ \\
\cline { 2 - 4 } Dual eligible & & $66.18 \%$ & $67.26 \%$ \\
Demographics & 78.52 & 78.61 & 55.57 & 61.52 \\
Age (mean years) & $74.41 \%$ & $80.97 \%$ & $61.43 \%$ & $70.62 \%$ \\
Female (\%) & $54.58 \%$ & $61.28 \%$ & $56.08 \%$ & $62.86 \%$ \\
Race or ethnicity & $16.64 \%$ & $30.27 \%$ & $18.95 \%$ & $29.04 \%$ \\
White & $11.32 \%$ & $22.30 \%$ & $10.48 \%$ & $21.21 \%$ \\
Black & $9.72 \%$ & $6.37 \%$ & $6.32 \%$ & $6.17 \%$ \\
Hispanic & $7.74 \%$ & $5.38 \%$ & $8.17 \%$ & $5.17 \%$ \\
Other race & & & & \\
Race unknown & & & & \\
\hline \hline
\end{tabular}

*Note: the total 2005 HCBS population includes children, while the analysis sample of CCDE population does not. 


\section{Figure 1: CCDE and data timeline}

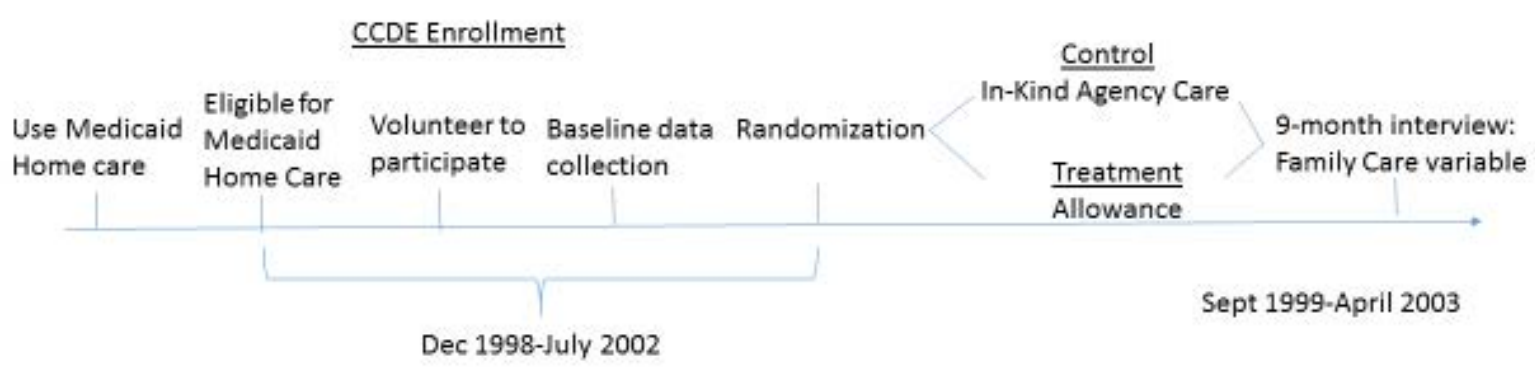

